\title{
Edward Malefakis (1932-2016) y sus semillas: España, la Europa del Sur y la historia agraria en perspectiva global
}

Romain Bonnet

\section{European University Institute, Florence}

Romain.Bonnet@eui.eu

Fecha recepción 15.05.2017 / Fecha aceptación 29.11.2017

\section{Resumen}

Este artículo demuestra la utilidad de la obra interdisciplinar de Edward Malefakis (1932-2016) para una historia agraria conjugando lo local con lo global. Las dos primeras partes se apoyan en los trabajos sobre España y Europa de este eminente historiador e hispanista. A continuación, analizaremos detalladamente, merced a un amplio abanico de fuentes inéditas, un ejemplo de «oligarquía rural» ya abordado por Edward Malefakis en su gran libro sobre la Segunda República española (1931-1936) y su dimensión agraria. Este estudio de caso permi-

\section{Abstract}

This article provides empirical evidence of how and why agrarian history, from the local to the global, can fruitfully inspire new perspectives on the outstanding research of the the American historian and hispanist Edward Malefakis (19322016). The first two parts are based on his work on Spain and Europe and open an epistemological discussion. The third part offers a careful analysis, involving a large array of original sources, of a case emphasised in Edward Malefakis's masterpiece on the Spanish Second Republic (1931- 
te volver sobre el fenómeno masivo de la violencia política rural y, más importante todavía, poner de manifiesto la dimensión europea y global de estos mundos predominantemente rurales. Todo este ejercicio analítico descansa sobre los cimientos de un uso ecléctico de la herramienta heurística del «excepcional normal». Al hacer dialogar lo cuantitativo y lo cualitativo, éste aparece como un provechoso útil historiográfico y epistemológico para articular lo local y lo global.

\section{Palabras clave}

Edward Malefakis, Historia agraria, Segunda República española, violencia, excepcional normal
1936) and its "rural oligarchy". Political violence is highlighted as a massive phenomenon in the predominantly rural world, situated in its European and global dimensions. In order to articulate the local and broader levels, this article establishes a dialogue between the quantitative and qualitative approaches mobilized in this empirical overview, and thereby introduces an innovative use of the heuristic category and epistemological tool of the "exceptional normal".

\section{Keywords}

Edward Malefakis, Agrarian History, Spanish Second Republic, Violence, Exceptional Normal 


\section{Introducción}

El 22 de agosto de 2016, en la isla mediterránea de Corfù, el historiador e hispanista estadounidense de origen griego Edward Malefakis falleció a los 84 años. Al día siguiente, en España, la prensa nacional le rindió homenaje. En la edición de El País, por ejemplo, José Álvarez Junco saludaba a «un maestro de historiadores de la II República», a «uno de los hombres más arrolladoramente atractivos que he conocido: simpático, inteligente, buen gourmet, gran conversador y carente, como pocos, de complejos», y precisaba: «Había nacido en 1932. Su padre era un emigrante griego llegado a los Estados Unidos allá por 1920» y «la madre apenas llegó a aprender inglés y siempre se comunicó con sus hijos en griego». ${ }^{1}$

En 1970, Edward Malefakis había publicado un gran libro de historia agraria de casi quinientas páginas titulado Agrarian Reform and Peasant Revolution in Spain: Origins of the Civil War. ${ }^{2}$ Había trabajado sobre éste entre 1960 y 1968, a partir de su tesis doctoral, Land tenure, agrarian reform and peasant revolution in Spain, que realizó en la Universidad Columbia de Nueva York, bajo la dirección de un especialista de la historia económica de Europa: Shepard Clough. En 1965 Edward Malefakis defendió su tesis y obtuvo el título de doctor. En 1972, el primer premio Herbert B. Adams de la American Historical Association recompensó su gran libro interdisciplinario de historia agraria. Edward Malefakis estaba a punto de cumplir los cuarenta años. En 1971, una editorial de Barcelona publicó su libro traducido al castellano con el título Reforma agraria y revolución campesina en la España del siglo $X X{ }^{3}$ Permanecía vigente el franquismo, con sus censuras y autocensuras. El vínculo entre la problemática agraria y los orígenes antidemocráticos de la guerra civil no aparecía de modo explícito en el título castellano, al contrario de la versión original en inglés.

«Fue una obra magistral, por su inteligencia y su ecuanimidad, que en nuestro mundo quedó objetivada como el Malefakis» expone José Álvarez Junco, precisando que, a través de esta gran problemática de historia agraria, el gran historiador e hispanista «en realidad trata-

1. J. Álvarez Junco, “Muere Edward Malefakis, maestro de historiadores de la II República”, El País, 23/08/2016, 21.

2. E. Malefakis, Agrarian reform and Peasant revolution in Spain. New Haven-London, 1970.

3. E. Malefakis, Reforma agraria y revolución campesina en la España del siglo XX, Barcelona, 1976 (1 ${ }^{\text {a }}$ edición española 1971). 
ba de todos los grandes problemas económicos y políticos de la década». ${ }^{4}$ Edward Malefakis «irrumpió, pues, en la historiografía de forma inusual, deslumbrante: empezando, literalmente, desde arriba», en palabras de Juan Pablo Fusi, para quién «el Malefakis», nada menos que «una de las mejores monografías que se hayan escrito sobre la historia española del siglo XX», fue una «obra maestra: un libro ambicioso, difícil, brillantemente escrito», ya que en éste trataba de «un tema capital: el problema agrario en la España del siglo XX». ${ }^{5}$ Este problema capital era un problema de Capital. Además, este primer libro fue «programático de toda su obra posterior, un semillero de ideas, un horizonte de brillantes posibilidades» al plantear la «Europa del sur, en la visión de Malefakis, como realidad histórica propia y distinta [...] como ámbito privilegiado de análisis, como geografía de estudio». ${ }^{6}$ Sin embargo, esta gran problemática común a la Europa meridional, que llamó la atención de Edward Malefakis a raíz de su caso de estudio español, esta vez no se tradujo "de forma preferente en libros». ${ }^{7}$

De 1970 en adelante, Edward Malefakis trabajó en una historia comparada del Sur de Europa incluyendo España, Portugal, Italia y Grecia. «No llegó a completar el libro prometido sobre este tema», notaba también José Álvarez Junco, quien revelaba esta broma seria del historiador e hispanista estadounidense contra los modos de producción historiográficos cada vez más dominantes: «Conozco a muy pocos [...] capaces de escribir dos buenos libros».8 Ahora bien, en 1991, desde el Instituto Juan March de Madrid Edward Malefakis (1992) realizó en inglés un trabajo bajo forma de paper titulado «Southern Europe in the 19th \& 20th Centuries: a Historical Overview». En 2000, el premio Elio Antonio Nebrija de la Universidad de Salamanca le fue concedido. Iba a cumplir los setenta. En 2014, cuando le quedaban apenas dos años de vida, Edward Malefakis reunió muchos de sus artículos e intervenciones en un último libro titulado Agonía y redención: España y la Europa meridional. ${ }^{9}$

Se demuestra en este artículo que la obra de Edward Malefakis se amolda al «juego de escalas» que los historiadores y sociólogos han llamado "pensar por caso». ${ }^{10}$ Permite a nuestros relatos de historia agraria una mejor articulación de escalas - de lo local a lo global y viceversa - con un mejor entendimiento de los actores, de sus prácticas y sobre todo de sus significados. Por lo tanto, en este artículo se analizarán en primer lugar estos puntos de vista abiertos por «el Malefakis» respecto a la discusión epistemológica y valor de pensar por caso en historia agraria. En segundo lugar, se estudiarán los juegos de escalas permitidos por la cuestión meridional europea que tanto preocupó a Edward Malefakis de

\footnotetext{
4. Álvarez Junco, “Muere...” op. cit., 21.

5. J.P. Fusi, "Edward Malefakis como historiador", in E. Malefakis, Agonía y redención. España y la Europa meridional (siglos XIX-XX), Madrid, 2014, 11-14.

6. J.P. Fusi, "Edward Malefakis...”, op. cit., 13.

7. J.P. Fusi, “Edward Malefakis..., op. cit.,11.

8. J.P. Fusi, "Edward Malefakis..., op. cit., 11.

9. Malefakis, Agonía... op. cit.

10. J. Revel, Jeux d'échelles. La micro-analyse à l’expérience, Paris, 1996. El autor realizó todas las traducciones al castellano. J. Revel, J.C. Passeron (Eds.), Penser par cas. Raisonner à partir de singularités, Paris, 2005.
} 
1970 en adelante. Por fin, movilizando un muy amplio abanico de fuentes inéditas, y explorando su relación con el fenómeno masivo de la violencia política en el campo, se analizará a ras del suelo un caso «excepcional normal» que Edward Malefakis puso explícitamente de relieve al evocar la «oligarquía rural». ${ }^{11}$

Esta demostración pone de manifiesto el carácter interdisciplinar de la historia agraria ambiciosa, actual, útil. El análisis empírico del estudio de caso a ras del suelo en la tercera parte pone de manifiesto hasta qué punto, hoy más que nunca, los recientes debates alrededor de la violencia política rural en la España republicana siguen siendo epistemológicamente fructíferos a la escala europea ${ }^{12}$ En 2012, unos meses después de haber participado en dichos debates, y en relación con la cuestión del conocimiento de la decisiva violencia política en el crucial período de entreguerras europeo, Fernando del Rey Reguillo afirmaba sin ambages que hasta la fecha «la historiografía española no se ha destacado ni por la altura de sus debates intelectuales, ni por la abundancia de los mismos». ${ }^{13}$ Este artículo trata precisamente de indicar en qué medida una historia agraria ambiciosa permite seguir abriendo unos horizontes epistemológicos nuevos y útiles tanto a niveles españoles, europeos y globales, al unir el análisis del fenómeno clave y masivo de la violencia política rural con el caso español mejor contextualizado.

\section{«El Malefakis»: una gran problemática de historia agraria, una narración científica}

Lamentaba recientemente (2016) el actual presidente de la Sociedad Española de Historia Agraria (SEHA) que, en los últimos años, su especialidad se haya «fragmentado en historias aparentemente diferentes: rural, agraria, de la agricultura, etc.» cuyas divisiones «no tienen más fundamento que su incapacidad para construir un relato unificado de los fenómenos más significativos». ${ }^{14}$ La particularidad interdisciplinaria del gran libro de historia agraria de Edward Malefakis es precisamente que consigue unificar estos fenómenos significativos. Así, no se limita exclusivamente a una especialidad exclusiva, a una comarca historiográfica, sino que va mucho más allá, a partir de una gran problemática de historia agraria y de su narración científica abarcando el caso español. Medio siglo después de su publicación, la de-

11. E. Grendi, "Microanalisi e storia sociale”, Quaderni Storici, 12:35 (1977), 506-520, 512, Malefakis, Reforma... op. cit., 86.

12. R. Robledo, "Fernando Del Rey Reguillo, Paisanos en lucha. Exclusión política y violencia en la Segunda República española”, Historia Agraria, 53 (2011), 215-221, R. Robledo, "Sobre la equiviolencia. Puntualizaciones a una réplica", Historia Agraria, 54 (2011), 244-246, F. del Rey Reguillo, "Acotaciones a una crítica”, Historia Agraria, 54 (2011), 239-243.

13. F. del Rey Reguillo, "Revisionismos y anatemas. A vuelta con la II República”, Historia social, 72 (2012), 155-172, 155.

14. M. González de Molina Navarro, "Repensar la historia agraria”, Debates de la Sociedad Española de Historia Agraria, (http://seha.info/7/Repensar_la_Historia_Agraria.pdf), 2016, 11. 
mostración de Malefakis sigue en gran medida vigente y eficaz, al abrir horizontes de matices y de preguntas nuevas.

Recuperar la historia agraria de Edward Malefakis significa pues luchar útilmente contra la fragmentación caprichosa en áreas de especialización y/o localismos exclusivos. Éstos tienden a desconectar la narración histórica de su presente, así como la historia agraria con la vida social del campo. Por consiguiente, retomar la perspectiva de Edward Malefakis contribuye a «una renovación suficientemente amplia como para que vuelva [la historia agraria] a conectarse con el presente», ya que - siempre en palabras del actual presidente de la SEHA - «con la crisis del modelo de agricultura industrial ha sobrevenido también la crisis de los relatos y de la manera tradicional de hacer Historia Agraria». ${ }^{15}$ Restaurarla también significa apoyarse en una lectura pionera e interdisciplinaria de sus clásicos y de su recepción. Reforma agraria y revolución campesina de Edward Malefakis ofrece una clara oportunidad para ello. Por eso, a lo largo de esta primera parte se va a citar mucho esta obra, así como su impacto historiográfico.

En 1972, en la revista Études rurales el distinguido especialista francés de historia rural Pierre Barral no dudaba en empezar su reseña del libro de Edward Malefakis con las siguientes palabras: «Este libro de excepcional claridad se va a convertir en la obra de referencia fundamental sobre una cuestión muy compleja». ${ }^{16}$ La cuestión agraria, tan compleja, tan masiva, que Edward Malefakis trataba de manera científica tras muchas medidas cuantitativas conducía a visiones y explicaciones de conjunto propuestas a lo largo de su libro. Por lo tanto, era susceptible de interesar a historiadores procediendo de distintos horizontes. En 1972, el eminente historiador británico Eric Hobsbawm reseñó al libro de Edward Malefakis con un claro: «Que de una vez por todas conste que se trata del mejor libro sobre el tema y con distancia», y para mejor entender los movimientos sociales de los campesinos españoles sugería compararlos con sus parientes mediterráneos y meridionales de la vecina península italiana. ${ }^{17}$

A principios de los años 1970, en el Journal of Social History, la gran obra agraria de Malefakis suscitó una interesante controversia con su compatriota Gabriel Jackson, historiador e hispanista. Éste notaba los obvios méritos de una historia agraria de relevancia concretamente interdisciplinaria y la calificaba como «sin lugar a dudas el estudio más científico que en cualquier idioma se haya publicado sobre los problemas agrarios españoles», con «datos de grande importancia no sólo para historiadores sino también para geógrafos, economistas y antropólogos». ${ }^{18}$ Sin embargo, Gabriel Jackson criticaba que «el uso de las estadísticas se hace confuso y potencialmente engañoso», y se preguntaba: «iNo correremos, como his-

15. González de Molina Navarro, "Repensar..., op. cit., 11.

16. P. Barral, "Malefakis, Edward, Agrarian reform and Peasant revolution in Spain (compte-rendu)", Études rurales, 48:1 (1972), 181-182.

17. E. Hobsbawm, "Malefakis, Edward, Agrarian reform and Peasant revolution in Spain (review)", Political Science Quartely, 87:2 (1972), 298-299, 198.

18. G. Jackson, "Malefakis, Edward, Agrarian reform and Peasant revolution in Spain (review)", Journal of Social History, 6:3 (1973), 381-385, 381. 
toriadores, el peligro de engañar a nuestros lectores con el uso de estos números $[\ldots]$ ?». ${ }^{19}$ También llamaba la atención el crítico de Edward Malefakis sobre un inextricable tríptico - violencia política rural, el derecho liberal instituido e intereses agrarios constituidos. Para Gabriel Jackson las interacciones sociales y las prácticas de actores de este tríptico podían ser aún más pormenorizadas. ${ }^{20}$

Respondió Edward Malefakis en una carta dirigida al editor del Journal of Social History. Lamentaba que Gabriel Jackson hubiera hecho a través de la reseña de su libro «un ataque velado hacía los enfoques cuantitativos de la historia», y afirmaba que dicho enfoque «tenía límites obvios, pero podía ser sumamente útil, en particular porque había sido muy despreciado en el pasado». ${ }^{21}$ Los tiempos cambian. "Una de las virtudes cardinales del enfoque cuantitativo» es que «al proporcionar datos concretos que pueden verificarse más fácilmente que las generalizaciones laxas de los historiadores» afirmaba Edward Malefakis, indicando que esto permite «adquirir una base» de discusión científica. ${ }^{22}$ Por consiguiente, más allá de los números, la cuestión de la relación entre lo particular y lo general es clave para la gran problemática de historia agraria e interdisciplinaria de Edward Malefakis, que en muy larga medida sigue vigente hoy. En ésta, la discusión metodológica sobre los números no puede disimular la crucial conversación epistemológica acerca de los problemas fundamentales, masivos.

De hecho, en su gran libro de historia agraria sobre la Segunda República española, Edward Malefakis hacía hincapié en el predominio de la concentración de la gran propiedad agraria. También, quizá en menor medida, insistía en la compleja imbricación de poderes e intereses, cuyos actores y prácticas impidieron que se llevasen a cabo las reformas sociales republicanas (así como, retrospectivamente, la comprensión histórica del fenómeno). «Los mismos factores que aconsejaban una redistribución de la tierra se oponían al éxito de cualquier programa ambicioso» notaba. ${ }^{23}$ Esta crucial problemática agraria del poder político en los mundos rurales predominantes en la España de entreguerras (como en buena parte de Europa, así como del mundo en el periodo de entreguerras) implicaba, por definición, una dimensión de masas. «Durante toda la primera mitad del siglo XX, España siguió siendo lo que siempre había sido: un país básicamente agrícola» exponía Edward Malefakis, precisando que esto era "cierto tanto económica como demográficamente» ${ }^{24}$ Sin embargo, notaba acertadamente Edward Malefakis que, desde un punto de vista histórico, fue precisamente «en el siglo XX cuando el problema social se ha vuelto central en las políticas españolas», no antes. ${ }^{25}$

19. Jackson, “Malefakis, Edward...”, op. cit., 382.

20. Jackson, "Malefakis, Edward..., op. cit., 384.

21. E. Malefakis, "Letter to the editor", Journal of Social History, 7:1 (1973), 110-111.

22. Malefakis, “Letter..., op. cit., 111.

23. Malefakis, Reforma... op. cit., 118.

24. Malefakis, Reforma... op. cit., 25.

25. E. Malefakis, “Spain: 1808-1936, by Raymond Carr (review)”, Political Science Quarterly, 85:2 (1970), 311-312. 
La gran problemática de historia agraria tratada interdisciplinariamente por Edward Malefakis implica, junto con sus dimensiones masivas, una minoría influyente económica y políticamente. Por ejemplo, el autor se hacía eco del dato medido y cuantitativo que escandalizó a los contemporáneos republicanos en el periodo de entreguerras: 99 de los 262 Grandes de España monopolizaban más de medio millón de hectáreas, lo cual contrastaba muy fuertemente con los millones y millones de campesinos españoles y ciudadanos republicanos total o parcialmente desprovistos de tierras. ${ }^{26}$ Además, proponía el historiador estadounidense el concepto de «absentismo moral» para caracterizar la actitud de estos propietarios influyentes, aunque matizaba que «el inveterado poderío rural de la nobleza, a pesar de ser también notablemente exagerado por la opinión pública, no era un mito». ${ }^{27}$

Por lo demás, Edward Malefakis demostraba que las lentas deliberaciones legislativas acerca de la ley de reforma agraria republicana acabaron implicando a ochenta mil propietarios, «en un país en el que no existían más que diez o doce mil grandes propietarios agrícolas». ${ }^{28}$ Precisaba que «120 años después de que las Cortes de Cádiz aprobasen las primeras leyes desamortizadoras, la aristocracia continuaba siendo una importante clase terrateniente», indicando que la naturaleza de sus vínculos con los otros propietarios quedaba por investigar. ${ }^{29}$ Esta historia agraria, que involucra el análisis de las sociabilidades y de los actores a pequeñas y grandes escalas, sigue vigente, más aún en nuestras sociedades contemporáneas de «orientación fundamentalmente urbana», tan vecinas y tan lejanas a la vez. ${ }^{30}$

El historiador e hispanista estadounidense evocaba acertadamente «los bloques de propiedad que determinan el poder económico y social de sus propietarios». ${ }^{31}$ Más allá de los números, tal poder era eminentemente político. Edward Malefakis veía en el comportamiento de los diputados de la llamada minoría agraria «la razón más importante de la extraordinaria duración y complejidad de los debates» parlamentarios (entre mayo y septiembre 1932, quince meses después de haberse proclamado la Segunda República) acerca de la reforma agraria, lo que contrastaba con la urgencia de las masas campesinas y ciudadanas españolas. ${ }^{32}$ Este "pequeño grupo de veinticuatro diputados» estaba llevando a cabo una clara «campaña de obstrucción». ${ }^{33}$ Por consiguiente, el poder de la gran propiedad parecía paradójicamente más político que el poder del parlamento.

Por lo demás, a través de los métodos cuantitativos que dominaba, el autor escogía una dimensión geográfica, ya que «el Sur representa 45,5 por ciento de la superficie labrada de España y comprende más de las tres cuartas partes de sus grandes fincas». ${ }^{34} \mathrm{Al}$ no limitarse esta

\footnotetext{
26. Ver Malefakis, Reforma... op. cit., 264, 265, 122.

27. Malefakis, Reforma... op. cit., 106, 89.

28. Malefakis, Reforma... op. cit., 258.

29. Malefakis, Reforma... op. cit., 91.

30. E. Malefakis, "Los campesinos, la política y la guerra civil en España 1931-1939", Agricultura y sociedad, 8 (1978), 9-60, 9.

31. Malefakis, Reforma... op. cit., 42.

32. Malefakis, Reforma... op. cit., 292.

33. Malefakis, Reforma... op. cit., 292.

34. Malefakis, Reforma... op. cit., 102.
} 
dimensión geográfica a ninguna región de España, y al tener muchísimos matices internos y externos, aparece como una componente de una cuestión meridional europea abarcando la península ibérica pero no limitándose a ésta. "Cualquiera que sea el módulo empleado, puede demostrarse el predominio absoluto de la gran propiedad en el Sur» escribía sin ambages (y demostraba cuantitativamente) Malefakis. ${ }^{35}$ «Las grandes propiedades controlaban una proporción de la superficie cultivada dos veces y media mayor en el Sur que en el resto de España» notaba el autor, invocando la larga duración mediterránea para entender estos espacios de grandes escalas marcados por la gran propiedad: «Su importancia en la vida económica y social de Andalucía, Extremadura y la Mancha era, hasta hace poco, comparable a la de los latifundia de la Roma antigua». ${ }^{36}$

Sin embargo, era «en la historia y no en la geografía del Sur donde hay que buscar las verdaderas raíces del sistema de latifundia», ya que «la historia del sur de España a partir de 1850 es la historia de unos hombres», seguía Edward Malefakis, «que trataron de revisar - o destruir - una estructura de propiedad que otros hombres - y no la geografía - había creado en siglos anteriores». ${ }^{37}$ Para Malefakis, era necesario pensar primero el tiempo para entender este espacio mediterráneo, contemporáneo y europeo. Este esfuerzo epistemológico y esta línea de investigación siguen siendo necesarios y útiles.

En la primera página de su prólogo, Edward Malefakis reconocía los principales horizontes de su gran libro: «Desearía haber aprendido más sobre la dinámica de la protesta campesina», confesaba sus límites: «Temo que en algunos casos pueda no haber sido lo suficientemente generoso en la interpretación de la complejísima postura de los anarcosindicalistas y sindicalistas». ${ }^{38}$ Las dimensiones políticas y sindicales que invocaba el autor remiten a la historia agraria. En cuanto a la cuestión de la «generosidad», detrás de la connotación moral de ésta aparecen en realidad las dimensiones epistemológicas y metodológicas. Remite sobre todo al fenómeno masivo del inédito recrudecimiento de la violencia política en el campo durante la República. «Durante los dos primeros años de la República estallaron centenares de disturbios en pueblos aislados de Andalucía» notaba Edward Malefakis. ${ }^{39}$ La cifra sube aún más si se sale de esta dimensión local y regional, para tomar en cuenta el entero panorama rural español, empezando por las otras regiones meridionales señaladas por el autor, también profundamente marcadas por la gran propiedad, y más abandonadas por la historiografía. ${ }^{40}$

«No tendría ningún sentido intentar establecer una lista de todos estos incidentes» de violencia política rural afirmaba Edward Malefakis que, sin embargo, como si el fenómeno general de la violencia política rural desbordase su marco metodológico cuantitativo, inten-

35. Malefakis, Reforma... op. cit., 34.

36. Malefakis, Reforma... op. cit., 34 .

37. Malefakis, Reforma... op. cit., 70, 85.

38. Malefakis, Reforma... op. cit., 9.

39. Malefakis, Reforma... op. cit., 351.

40. Ver M. P. Ladrón de Guevara Flores, F. Alía Miranda, "Movimiento obrero y conflictividad social en Castilla-La Mancha (1898-1936)”, en M. Ortiz Heras, D. Ruiz, I. Sánchez Sánchez. (Eds.), Movimientos sociales y estado en la España contemporánea, Cuenca, 2001, 529-564, 552. 
taba paradójicamente justificar su enfoque: «pero, además, esta lista no podrá completarse sin llevar a cabo un estudio sistemático de la prensa local y provincial», haciéndolo además algo forzadamente: «lo que habría requerido un esfuerzo hercúleo que se hallaba más allá de mis capacidades». ${ }^{41}$ Por consiguiente, justificar científicamente y cuantitativamente algo pretendidamente sin sentido, es a veces indicar la existencia de una posibilidad nueva de conocimiento. Al pensar por casos a la vez particulares y paradigmáticos, el esfuerzo de análisis de la violencia política rural se vuelve sobre todo epistemológico. Permite establecer concretamente un indispensable diálogo empírico entre lo cuantitativo y lo cualitativo, a partir de unos casos que la revelan y catalizan, de unos casos «excepcionales normales». ${ }^{42}$

Cuando Edward Malefakis publicó su primer libro, este concepto elaborado desde la microstoria no existía. Por consiguiente, hoy las nuevas generaciones de historiadores pueden combinar y pormenorizar la visión de conjunto de la historia agraria cuantitativa con esta útil y relativamente nueva herramienta metodológica. Por lo demás, notaba Edward Malefakis que la reforma agraria como política podía sólo formar parte de una realidad histórica, simbólica y jurídica más amplia. Muy lentamente elaborada y aplicada, aunque «más moderada que mucha de la legislación de la "Revolución Verde" en los países del este de Europa» después de la Revolución bolchevique, rusa e internacionalista de 1917, la ley de reforma agraria republicana comportaba sin embargo en sus principios sociales «una transformación tan profunda del sistema de propiedad de la tierra existente en aquel momento, que hay que considerarla revolucionaria por sus implicaciones», pues «amenazaba seriamente a la clase económica más fuerte del país». ${ }^{43}$

Además, los llamados decretos del trabajo (precisando colectivamente y por contrato, de manera inédita, los derechos de los trabajadores agrícolas y las obligaciones de los propietarios), al haberse promulgado desde el Ministerio de Trabajo inmediatamente en las semanas consecutivas a la proclamación de la Segunda República, «representaron una revolución sin precedentes para la vida rural española», por su «amplitud» combinada con la «rapidez» con la que fueron promulgados y que contrasta «con lo que iba a pasar más tarde», con la reforma agraria. ${ }^{44}$ "Se crearon nuevas condiciones de vida en el campo» con estos decretos, «mucho antes de que el proyecto de reforma agraria llegase a las Cortes para su discusión», aunque por supuesto «ninguno de los decretos se aplicó con la severidad de su forma primitiva». ${ }^{45}$ Estas dos caras de la ley y sus implicaciones para la violencia política rural quedan por investigar, con respecto al paro masivo del campesinado español, que motivó esta legislación social históricamente inédita. ${ }^{46}$

«Acaso el deber más desagradable del historiador es la necesidad de atribuir la responsabilidad de acontecimientos históricos complejos» empezaba Edward Malefakis en su

\footnotetext{
41. Malefakis, Reforma... op. cit., 351, 352.

42. Grendi, “Microanalisi...” op. cit., 512.

43. Malefakis, Reforma... op. cit., 243, 297.

44. Malefakis, Reforma... op. cit., 204.

45. Malefakis, Reforma... op. cit., 204, 203.

46. Ver Malefakis, Reforma... op. cit., 205.
} 
capítulo conclusivo, consciente de que tras los «compartimentados juicios», que por definición resultan del relato del historiador, y «por mucho que lo intente», éste «no puede hacer justicia plena de los laberínticos acontecimientos que ha estado tratando». ${ }^{47} \mathrm{El}$ autor citaba la frase de Charles Kingsley para quien «la historia es un hatajo de mentiras perpetradas por los vivos a costa de los muertos», precisando una epistemología que cabría calificar de constructiva a través de una definición en términos negativos: «la única defensa que hago en favor de las observaciones que siguen es que me parecen menos carentes de veracidad que muchas otras que pueden hacerse (y que se han hecho)». ${ }^{48}$ Medio siglo después de su primera publicación, y obviamente pese a útiles matices, este libro y su gran problemática interdisciplinaria implicando la historia agraria española resisten al tiempo. Además, permiten un juego de escalas indispensable para mejor conectar los relatos de esta realidad española con su presente europeo y global.

\section{Edward Malefakis: del caso español a la cuestión meridional europea, y viceversa}

«Los grandes hombres son útiles para la ciencia durante la primera mitad de su vida, y dañinos durante la segunda mitad» bromeaba seriamente el epistemólogo francés Gaston Bachelard.$^{49}$ En 1972, cuando su gran libro de historia agraria sobre España fue traducido al castellano, Edward Malefakis entraba en su 40 aniversario. Pasó las cuatro décadas siguientes trabajando sobre la Europa del Sur, sobre una cuestión meridional europea que implica no sólo España, sino también Portugal, Italia y Grecia. A través de la gran problemática agraria y de la demostración contenida en su obra principal sobre el caso español, Edward Malefakis había conseguido hacer existir de manera implícita una visión de conjunto, a la vez europea y global.

En sus interesantes trabajos sobre la Europa del Sur posteriores a Reforma agraria $y$ revolución campesina, de los que, al contrario de esta obra fundamental, no salieron libros destacados, el historiador e hispanista estadounidense reivindicó una visión de conjunto, esta vez de manera explícita (mientras era ya presente en la demostración de su primer libro, pero de manera implícita). Al contrario, la atención inicialmente explícita que pagó a la historia agraria se volvió cada vez más implícita. A la luz de esta trayectoria, cabe desvelar los nexos existentes entre las peculiaridades de la historia agraria escrita por Edward Malefakis sobre el caso español, y la dimensión general de la cuestión meridional europea a la que dedicó posteriormente su atención científica. Por eso, en esta parte vamos a citar abundantemente su obra dedicada a esta cuestión y que fue escrita de 1970 en adelante, hasta la publicación de su último libro en 2014, en el que se reúnen varios de sus estudios sobre la Europa meridional.

47. Malefakis, Reforma... op. cit., 442.

48. Malefakis, Reforma... op. cit., 442.

49. G. Bachelard, La formation de l'esprit scientifique Paris, 1993 (1 edición 1934), 17. 
Llama mucho la atención el hecho de que Edward Malefakis al referirse a ésta en 2014 apenas aludiera al predominio de la concentración de la gran propiedad agraria, que sin embargo tanto lo había ocupada anteriormente. «Las zonas de grandes propiedades ocupaban el 44 por ciento del territorio en España y el 40 por ciento de Portugal» aparece, en este sentido, como una de las pocas líneas comparativas que se encuentra en su obra posterior a 1970, mientras, paradójicamente, la atención científica dedicada a la gran propiedad en el caso español había contribuido a la fuerza científica de la demostración que le hizo famoso. ${ }^{50}$

Además, esta matriz comparativa contemporánea implica una dimensión meridional, a la vez regional, nacional y europea, en toda la península ibérica incluyendo España y Portugal, especialmente por debajo del río Tajo. ${ }^{51}$ En el caso italiano también se encuentra una dimensión meridional a la vez regional, nacional y europea. «La cuestión social, en Italia, iba a coincidir con la cuestión meridional», desde finales del siglo XIX en adelante, exponía por ejemplo Piero Bevilacqua, mientras Luigi Masella evocaba el muy tardío reconocimiento historiográfico de los jornaleros del Sur, a finales del siglo XX.52 También en Grecia se encontraba, al menos desde el último cuarto del siglo XIX, una cierta imbricación entre una cuestión meridional y el predominio de la concentración de la gran propiedad agraria. ${ }^{53} \mathrm{He}$ aquí, para la historia agraria ambiciosa, una matriz comparativa contemporánea nueva y significativa, a la vez europea y global.

Edward Malefakis, al trabajar sobre el sur de Europa reivindicaba explícitamente una visión de conjunto, que aparecía, por ejemplo, ya desde el título del paper que presentó en 1991 en el Instituto Juan March de Madrid: «Southern Europe in the 19TH \& 20TH Centuries: An Historical Overview». ${ }^{54}$ Empezaba este trabajo con la frase: «Hace cerca de veinte años, a principios de los años setenta, un término nuevo entró en el vocabulario académico: Europa del Sur», y precisaba que los límites del término eran flexibles, incluyendo eventualmente Francia o la península balcánica, aunque «en la mayor parte se refiere a cuatro países: Portugal, España, Italia y Grecia». ${ }^{55}$ Ahora bien, el autor no utilizaba la construcción de una matriz comparativa acerca de la historia agraria para plantear la cuestión meridional europea entre similitudes y diferencias. En cambio, anunciaba una forma de narración historiográfica según él minoritaria: «Voy a desafiar el predominante desdeño para la historia narrativa». ${ }^{56}$

50. Malefakis, Agonía... op. cit. 353.

51. Ver D. Palacios Cerezales, "Um caso de violência política: o 'Verao Quente' de 1975", Análise Social, 37:165 (2003), 1127-1157, 1128.

52. P. Bevilacqua, Breve storia dell'Italia meridionale dall'Ottocento a oggi, Roma, 1993, 74, L. Masella, "Braccianti nel sud: una ricognizione storiografica", in P. P. D’Attorre, A. De Bernard, Studi sullagricoltura italiana: società rurale e modernizzazione, Milano, 1994, 195-222.

53. Ver E. Karouzou, "Las reformas agrarias en Grecia, siglos XIX y XX", Noticiario de historia agraria, 6 (1993), 59-83, 60.

54. E. Malefakis, "Southern Europe in the 19TH \& 20TH Centuries: An Historical Overview" (Juan March Institute: Working paper, 1992).

55. Malefakis, "Southern Europe..., op. cit., 1.

56. Malefakis, “Southern Europe..., op. cit., 4. 
Dicho desdeño para una forma de narración minoritaria fue también señalado como obstáculo para la historia comparada buscando empíricamente las causas «que tuvieron una acción general, las únicas reales». ${ }^{57}$ De hecho, la visión de conjunto aparece fuertemente vinculada a la forma comparativa de la narración científica.

Edward Malefakis insistía sobre la dimensión contemporánea de una cuestión meridional europea. Más allá del localismo exclusivo de las fronteras nacionales y dominantes, ésta implicaba unas dimensiones comunes a la vez política y económica. «La República española fracasó al final, como lo hicieron 13 de las 14 otras Repúblicas establecidas en Europa entre 1910 y 1931» notaba. ${ }^{58}$ Además, este fenómeno a la vez político y económico abarcaba una clara dimensión meridional, que sin embargo no se limitaba exclusivamente a la Europa del sur. «En tres años y medio, entre Octubre 1922 y Mayo 1926, Italia, España y Portugal habían caído bajo dictaduras» indicaba, señalando que dichas dictaduras formaban parte de un «fenómeno Europeo general». ${ }^{59}$ Tampoco escapaba al autor esta otra concomitancia del siglo XX y notaba que entre 1974 y 1975 cayeron «en un espacio de 19 meses, los regímenes dictatoriales de Portugal, Grecia y España». ${ }^{60}$

En 2014, Edward Malefakis evocaba, más contemporáneamente aún, «el apodo insultante de PIGS [...] que se inventó alrededor de 2009» para designar a Portugal, España, Italia y Grecia, añadiendo: «Creo que ya ha establecido la legitimidad de Europa meridional en el mundo actual. (...) La Europa del Sur puede considerarse un concepto regional». ${ }^{61}$ "Desarrollar el concepto de una Europa meridional enriquecería la historiografía europea», lo haría quizás más aún junto con el concepto de cuestión meridional europea, esto es como gran problemática de historia agraria contemporánea, a la vez comparativa, global y transnacional. ${ }^{62}$ De hecho, esta problemática de historia agraria conduce a «escribir una historia con las Naciones que no sea una historia de las Naciones», arbitrariamente limitada por la exclusividad de dimensiones locales. ${ }^{63}$

Por lo demás, insistía Edward Malefakis en la existencia de una matriz comparativa significativa, que por lo menos implicaba tres países del Sur de Europa desde finales del siglo XIX en adelante. El «trasformismo» italiano, el «rotativismo» portugués y el «caciquismo» español eran, en palabras del autor, formas de «corrupción» institucionalizadas en los correspondientes Estados por «las clases dominantes», cuyas prácticas producían y reproducían nada menos que una «corrupción sistematizada al nivel nacional». ${ }^{64}$ En 2000 y 2014, Edward

57. Heinz-Gerhard Haupt, "Comparative history. A contested method ", Historik tidskrift, 127:4 (2007), 697-716, M. Bloch, 'Pour une histoire comparée des sociétés européennes', Revue de synthèse historique, 46:6 (1928), 15-50, 45.

58. Malefakis, Agonía... op. cit., 109.

59. Malefakis, "Southern..." op. cit. 42.

60. Malefakis, Agonía... op. cit., 309.

61. Malefakis, Agonía... op. cit., 310.

62. Malefakis, Agonía... op. cit., 384.

63. P.-Y. Saunier, Transnational History, Nueva York, 2013, 8.

64. Malefakis, “Southern...” op. cit., 21, 22, 25. 
Malefakis seguía escribiendo sin ambages que «el liberalismo oligárquico que gobernaba en España entre 1875 y 1923 era paralítico y decadente». ${ }^{65}$ Por consiguiente, la dimensión regional de la cuestión meridional europea remite a las dimensiones a la vez políticas y económicas del concepto de liberalismo.

Por supuesto, la historiografía reciente ha matizado seriamente esta problemática del Estado liberal, que no se limitaba al Sur de Europa, ni tampoco al periodo de entreguerras. ${ }^{66}$ También se ha pormenorizado la interpretación del origen del corporativismo en las violentas dictaduras del sur de Europa en el siglo XX. Edward Malefakis lo atribuía al doble peso de la Iglesia y del ejército imbricado en estas sociedades combinado con «el decisivo papel que este concepto había tenido en el pensamiento social católico desde la década 1890». ${ }^{67}$ Recientes comparaciones insisten también o más bien sobre puntos comunes decisivos e inherentes a los predominantes mundos rurales del Sur y del Este de Europa. ${ }^{68}$ Los aspectos agrarios de la cuestión meridional europea remiten a un espacio en construcción.

«El paradigma regional predominante de Europa a lo largo de la mayoría de su historia ha sido el de norte-sur» escribía Edward Malefakis. ${ }^{69}$ Pormenorizaba esta visión del espacio al evocar una «división tripartita fundamental» con una Europa «urbana, comercial e industrial» al Norte, una Europa «masivamente agrícola» al este y una «zona intermedia» en la Europa del Sur. ${ }^{70}$ También el historiador e hispanista evocaba la transperiodicidad de una cuestión meridional europea, localizada en la larga duración del medio milenio moderno y contemporáneo, al afirmar que «la decadencia de Europa del Sur en general no empezó de verdad hasta el siglo XVII». ${ }^{71}$ Por supuesto, cabe hoy poner en tela de juicio los conceptos vinculados a imágenes cuyas dimensiones negativas se pueden revelar arbitrarias.

La manera más científica de hacerlo radica sin duda en la interrogación comparativa de dichas representaciones negativas, ya que aparecieron de manera concomitante para designar varios espacios del Sur de Europa, más allá de las fronteras regionales y/o nacionales. ${ }^{72}$ A la luz de los trabajos existentes también parecen mejorables las propuestas narrativas de extrañas connotaciones esotéricas y morales, como «lo que cabría llamar la maldición de la Europa del Sur» respecto a la supuesta «decadencia», mientras se pretendía ver el periodo de

65. Malefakis, Agonía... op. cit., 304.

66. Ver J.-L. Briquet, "Clientelismo e processi politici”, Quaderni Storici, 97:1, (1998), 9-30, R. Camurri, "La Italia liberal y la España de la Restauración: una perspectiva comparada”, in R. A. Gutiérrez, R. Zurita, R. Camurri (Eds.), Elecciones y cultura política en España e Italia (1890-1923), Valencia, 2003, 15-32.

67. Malefakis, Agonía... op. cit., 336.

68. Ver D. Riley, The Civic Foundations of Fascism in Europe: Italy, Spain and Romania, 1870-1945, Baltimore, 2010.

69. Malefakis, Agonía... op. cit., 311.

70. Malefakis, Agonía... op. cit., 379, 380.

71. Malefakis, Agonía... op. cit., 314.

72. Ver para el caso italiano N. Moe, The View from Vesuvius. Italian Culture and The Southern Question Londres, 2002, J. Dickie, Darkest Italy. The Nation and Stereotypes of the Mezzogiorno, 1860-1900, Nueva York, 1999. 
la guerra fría («1950-1992») como una «redención» o una «trascendencia».73 Aquí también, la manera más científica de desprender de los estereotipos las narraciones de la historia agraria parece radicar en la visión de conjunto rigurosamente construida comparativa y transnacionalmente. «Para entender de verdad [España en el siglo XX] hay que entender también lo que ocurrió en Europa en su totalidad» en palabras del propio Edward Malefakis. ${ }^{74}$

Respecto a los cruciales y violentos años de entreguerras, tan decisivos para la historia del siglo XX en su globalidad, el historiador e hispanista estadounidense proponía el interesante concepto de "clima de opinión europeo», transnacionalmente producido, a escala global, por la «"revolución verde" del Este de Europa durante los años 20» que, en particular al nivel simbólico y global, repercutió en estas sociedades marcadas por mundos rurales entonces predominantes. ${ }^{75}$ Por consiguiente, esta corriente transnacional del siglo XX parece imbricada en la más amplia época contemporánea con «la influencia del contexto Europeo sobre España» que «ha sido enorme, posiblemente más que cualquier época de la historia». ${ }^{76}$ De hecho, en la época contemporánea Edward Malefakis notaba una dirección dominante de los intercambios transnacionales significativos, desde el Norte hacía el Sur de Europa, a través de un bastante inédito "grado de influencia». ${ }^{77}$ Notaba el autor que esta situación contemporánea contrastaba con las anteriores influencias europeas a escala global ya que, en la larga duración, éstas procedían más bien de las sociedades mediterráneas. ${ }^{78}$

Por lo demás, el historiador e hispanista observaba el hecho de que a lo largo del siglo XX la economía se había vuelto en larga medida simbólica, desmaterializada, pero con jerarquías y desigualdades siempre presentes en el espacio de influencia de estos intercambios: "Otro factor que hizo la población del sur más receptiva a las influencias exteriores fue el considerable crecimiento de los sistemas educativos». ${ }^{79}$ Por consiguiente, la cuestión meridional europea implica un enfoque reflexivo de la cuestión agraria, como fenómeno global en la época contemporánea y, también, como problema historiográfico crucial para el método comparativo y/o para la perspectiva transnacional. Se trata de pensar el espacio en construcción de la cuestión meridional europea y, tras la edificación de éste, las «categorías del pensamiento impensadas que delimitan lo pensable y predeterminan lo pensado» ${ }^{80}$ En consecuencia, la cuestión de escalas remite a una cuestión de conceptos para la historia agraria deseando pensar de lo local a lo global y viceversa.

Cuando Edward Malefakis escribió su historia agraria y su historia de la Europa del sur, todavía no existían en las ciencias sociales las herramientas de la reflexividad. Ésta siempre

73. Malefakis, Agonía..., op. cit., 333, 340; Malefakis, "Southern..., op. cit.,55.

74. Malefakis, Agonía... op. cit., 303.

75. E. Malefakis, "Análisis de la Reforma agraria durante la Segunda República", Agricultura y Sociedad, 7 (1978), 35-51, 37, 38.

76. Malefakis, Agonía... op. cit., 303.

77. Malefakis, "Southern..." op. cit., 56.

78. Malefakis, Agonía... op. cit., 414.

79. Malefakis, Agonía... op. cit., 342.

80. P. Bourdieu, L. Wacquant, Réponses. Pour une anthropologie réflexive, Paris, 1992, 35.

Revista de historiografía 29, 2018, pp. 93-118 
implica una dimensión personal de compromiso científico del autor, al igual que la historia global a propósito de la práctica de la que Jürgen Osterhammel exponía recientemente haber querido reunir en «un solo libro [su]s intereses para todos los aspectos imaginables de la historia». ${ }^{81}$ Tras la cuestión meridional europea, la historia agraria desborda útilmente las especialidades tanto exclusivas como arbitrarias.

En 2014, Edward Malefakis afirmaba que, con la evolución demográfica y económica de nuestras sociedades contemporáneas, «el problema agrario perderá también significación política, no habiendo sido nunca resuelto, sino solamente trascendido». ${ }^{82}$ En esta alegación llama sobre todo la atención sobre la noción de política asociada con la de trascendencia. Cabría definir ésta como principio dinámico creador de inercia social móvil.

Trascendido por la cuestión meridional europea como concepto y como espacio en construcción, el «problema agrario» evocado por Edward Malefakis permite escribir una historia agraria global. Se trata de salir útilmente de las cortapisas tan a menudo vinculadas con lo específico y/o con la producción y reproducción de las engañosas anteojeras locales, regionales, y/o nacionales. Además, cabe mencionar aquí que tan temprano cómo en 1922 los historiadores empleando el método comparativo combatieron concretamente y explícitamente el «punto de vista etnocéntrico» como «lo que más se opone a la ciencia». ${ }^{83}$ Pensar por caso, al articular las escalas de la cuestión meridional europea abriendo estas perspectivas comparativas y transnacionales, es contribuir en plural a la escritura científica de la historia agraria de hoy y mañana.

\section{Oligarquía rural y violencia política: un caso excepcional normal}

Al evocar, en su gran libro de historia agraria sobre la Segunda República española, la oligarquía rural, Edward Malefakis destacó un caso particular y paradigmático: en la provincia de Toledo y en «el gran municipio de Ocaña (6.387 habitantes) cuatro miembros de la familia Silva Soria y otros tres propietarios poseían en total el 59 por ciento de las 8.792 hectáreas del municipio». ${ }^{84}$ Ocaña es la principal aglomeración rural de la comarca epónima, confinada en el este de la provincia de Toledo y muy marcada por la gran propiedad como todo sur de España. Comarca rural de proximidad sureña para los metropolitanos, la de Ocaña de hecho linda con la de Madrid al norte. Apenas una cincuentena de kilómetros separa la aglomera-

81. J. Osterhammel, The Transformation of the World. A Global History of the Nineteenth Century, Princeton-Oxford, 2013, Q. Deluermoz, M. König, "Entretien avec Jürgen Osterhammel”, Revue d'histoire du XIXème siècle, 46:1 (2013), 137-141, 138.

82. Malefakis, Agonía... op. cit.,373.

83. H. Pirenne, "De la méthode comparative en histoire", in G. Des Marez, F. Ganshof, Compte-rendu du Ve Congrès des Sciences Historiques Bruselas, 1923, 18-32, 29.

84. Malefakis, Reforma... op. cit., 96. Por supuesto, la lectura de un artículo basado en la articulación de las escalas de análisis puede y debe, para entender mejor su contexto, complementarse con algunos de los aspectos más interesantes de la historiografía local. 
ción rural de la capital española. Además, la comarca de Ocaña se toca con la provincia de Cuenca al este, y colinda con la comarca de Quintanar de la Orden al sur.

Forma parte de esta última y de la provincia de Toledo la aglomeración rural de Corral de Almaguer. A principios de febrero de 1932, fue organizada sobre unas propiedades de esta localidad una cacería en honor del General Sanjurjo, quien encabezó desde Sevilla el primer intento de golpe anti-republicano el 10 de agosto de 1932. Este ritual militarista de la cacería en honor de Sanjurjo ocurrió en el Monte de Mudela, cuyo propietario era Severiano de Silva y Soria. ${ }^{85}$ En este apartado, se analizará desde una perspectiva a ras del suelo este caso excepcional normal, sus actores, prácticas, sociabilidades, símbolos y rituales. Todas estas dimensiones resultan claves para explicar el fenómeno masivo de la violencia política rural. Como en tantos otros pueblos, también afectó al de Corral de Almaguer al principio de la Segunda República, en el que aparecía la sombra de la familia Silva y Soria, así como la del poder de la gran propiedad agraria y de sus asimetrías.

«Corral de Almaguer. - En los pasados días se celebró una cacería en honor del general Sanjurjo, que asistió acompañado de sus ayudantes». Así empezaba un artículo que acababa con la firma de «P. Gálvez», sobre la primera página de la edición del 5 de febrero 1932 del diario provincial El Castellano. Diario católico de información. Éste había sido fundado en Toledo en 1904, desde la Catedral Primada de España y bajo el impulso del Arzobispo de Toledo Ciriaco María Sancha y Hervás, primado de España y Patriarca de las Indias Occidentales, nombrado en 1898 por León XIII, el papa de la encíclica social-católica Rerum Novarum. ${ }^{86}$ El Castellano reivindicó alto y claro su propósito político exclusivista desde el principio: «Es necesario destruir la mala prensa [que] afecta el orden moral». ${ }^{87} \mathrm{~A}$ finales de diciembre 1935, pocos meses antes de pronunciarse el golpe anti-republicano, cuya violencia desencadenó la guerra civil española, cesó de publicarse.

A principios de 1932, el General Sanjurjo era el Director General de la Guardia Civil del régimen republicano. Ya lo había sido anteriormente, con el régimen monárquico, bajo el cual este héroe de las guerras coloniales fue también Alto Comisario en Marruecos. Después de los violentos sucesos de Castilblanco ocurridos el 31 de diciembre de 1931 en la provincia meridional de Badajoz, no muy alejada de la de Toledo, y también marcada por la gran propiedad agraria, el oficial había criticado públicamente el régimen republicano. «Calificó a los concejales socialistas de Extremadura de unos indeseables que ( ) aterrorizaban a los terratenientes» $\mathrm{y}$ «comparó a los trabajadores de Castilblanco con las tribus de moro contra las que había combatido en Marruecos», mientras «acusó de todo lo ocurrido a Margarita Nelken "siendo extranjera y judía"». ${ }^{88}$ Esta mujer había sido sobre todo portavoz, en la pro-

85. El Castellano. Diario católico de información, 05/02/1932, 1. En las referencias posteriores no se indicará el subtítulo (Diario...).

86. M. L. Picón García, "El Cardenal Sancha y Toledo. Acercamiento a los siete primeros años de su Arzobispado (1898-1904)”, Cuadernos del Salegar, 58-59 (2009), 1-23, 3.

87. El Castellano, 05/03/1904, p. 1.

88. P. Preston, The Spanish Holocaust. Inquisition and Extermination in Twentieth-Century Spain, Londres, 2012, 21, 53. 
vincia de Badajoz, de la Federación Nacional de los Trabajadores de la Tierra, el sindicado de los jornaleros.

Con esta comparación peyorativa para el campesinado pobre del sur de España, bien se ve que el espacio de la cuestión meridional europea remite, por definición, a ambas orillas del Mediterráneo. «Está España deliberando si se va a transformar en un régimen soviético o en una República disciplinada y culta y progresiva» afirmaba también el General Sanjurjo en El Castellano, que reproducía además su alegación insistiendo en que «la Guardia civil no ha estado ni está sometida a ningún caciquismo», así como otra dirigida a «los déficits de la cultura y de ciudadanía de ciertas poblaciones rurales» ${ }^{89}$ En la España de los años 1930, la violencia política rural remitía a la violencia verbal, y también a las sociabilidades y redes vinculadas a la gran propiedad.

«Tuvo lugar en el Monte de Mudela, ofrecida por su propietario Don Severiano de Silva» indicaba P. Gálvez a propósito de la cacería organizada en Corral de Almaguer en honor del General Sanjurjo a principio de 1932, precisando que «concurrieron personalidades de Ocaña, entre ellas el teniente de la Benemérita señor Pascual, y de otros pueblos». ${ }^{90}$ El teniente del acalde y varios concejales del ayuntamiento de la localidad estaban citados entre los invitados. Es de suponer que el propio P. Gálvez, que por lo menos en esta ocasión actuaba de corresponsal desde Corral de Almaguer para El Castellano, también estuviera invitado y que participara en el ritual que da a ver con un gran número de detalles y valoraciones:

Después del desayuno - unas típicas migas, ilustradas con lomo y chorizo- comenzó la cacería. ( ) El propietario de la posesión, señor Silva, dirigió a maravilla los ojeos como un gran montero. Amigos suyos, que son grandes escopetas, actuaron también brillantemente. Se cobraron 290 perdices y algunas liebres. El almuerzo - una gran paella y un sabroso cochifrito- estuvo a cargo de Ernesto, y todos tuvieron para él sinceros elogios.

Después de la cacería en las afueras del pueblo y sobre las propiedades de Severiano de Silva y Soria, el General Sanjurjo se trasladó al centro de la población donde «le esperaba una manifestación para rendirle un homenaje de afecto», en palabras de P. Gálvez, describiendo que «entre vítores y aplausos, el público le acompañó hasta el Ayuntamiento». Desde un balcón, el General Sanjurjo se dirigió a sus incondicionales, $\mathrm{y}$ «después el ayuntamiento le obsequió con un espléndido "lunch" durante el cual el General Sanjurjo saludó a las distinguidas señoritas de la localidad y a varios señores», y luego, en cambio, fueron dirigidas «elocuentes frases de elogio para el General Sanjurjo y para el benemérito instituto de la Guardia Civil». «Ya anochecido, el General Sanjurjo partió del pueblo entre entusiastas aclamaciones» concluía P. Gálvez, precisando que estaba «muy satisfecho por las gratas horas disfrutadas en Corral de Almaguer y muy reconocido a las manifestaciones de simpatía que recibió durante todo el día».

89. El Castellano, 07/01/1932, 1.

90. El Castellano, 05/02/1932, 1. Proceden de esta fuente las citas que siguen, hasta la próxima nota. 
Severiano de Silva y Soria, quien había invitado al General Sanjurjo a cazar sobre sus tierras a principio de 1932 (y quien formaba parte de una familia señalada por Edward Malefakis como paradigmática de la oligarquía rural) acumulaba el poder económico con el poder político. En octubre de 1912, era presentado por un periódico liberal de la vecina provincia de Cuenca como «diputado provincial» $\mathrm{y}$ «rico propietario», mientras se casaba con María Rosario Melgarejo y Baillo «en la capilla particular de la magnífica finca "Las Cruces", propiedad de los marqueses de Melgarejo». «Los novios marcharon en automóvil a Madrid, y de allí saldrán para el extranjero» concluía el artículo. ${ }^{91}$ Una niña nació poco después del matrimonio. En febrero del 1922, María de las Mercedes de Silva y Melgarejo, la hija de Severiano de Silva falleció a los ocho años y fue sepultada el cementerio de la Sacramental de San Lorenzo en Madrid. ${ }^{92}$

Adinerado diputado provincial, propietario vinculado con la aristocracia, Severiano de Silva no tenía nada en contra de un cierto regionalismo. En enero de 1915, era el representante de la diputación provincial de Cuenca para la Asamblea de Zonas Neutrales prevista unos días después en Valladolid. ${ }^{93}$ Debía reunir las provincias exportadoras de productos (principalmente agrícolas) cuyos propietarios se estaban enriqueciendo gracias a la Primera Guerra Mundial. Su proyecto presentado en las Cortes del Reino de España precisaba que se trataba de «dotar al comercio, la agricultura y las industrias de España de un arma indispensable» para «provocar una fuerte corriente de exportación en la ocasión ofrecida por el conflicto europeo, que sería inadvertencia suicida dejar perder». ${ }^{94} \mathrm{El}$ regionalismo económico y comercial abarcando la dimensión agrícola remitía a los nacionalismos políticos y bélicos, directos o indirectos, centrales o periféricos. Hasta en la «neutralidad» la Primera Guerra Mundial fue su violencia.

En 1920, Severiano de Silva, quien era además abogado, había sido elegido diputado del Reino de España por la facción conservadora en la provincia de Cuenca. ${ }^{95}$ Tras esta función, en 1923 formó parte de instituciones cercanas a la Unión Mercantil de Cuenca, junto con el General Fanjul, diputado de la facción maurista en la misma provincia (y golpista nacionalista en 1936). ${ }^{96}$ En febrero de 1931, mientras se preparaban las últimas elecciones legislativas del Estado liberal bajo el Reino de España, la candidatura de Severiano de Silva y Soria era anunciada en el distrito de Tarancón de la provincia de Cuenca, esta vez bajo la etiqueta «Regional agrario». ${ }^{97}$ Por consiguiente, la dimensión regional y/o provincial parece una de las pocas constantes en la carrera política y personal de este gran propietario español, junto con el compromiso comercial y las uniones entre distinguidas familias.

91. El liberal (Cuenca), 23/10/1912, 1. Proceden de esta fuente las citas que siguen, hasta la próxima nota. 92. Ver $A B C, 24 / 02 / 1922,29$.

93. Ver El día de Cuenca. Periódico independiente, regional y de información, 08/01/1915, 2.

94. J. Pabón, Cambó 1876-1947, Barcelona, 1999, 348.

95. Ver el índice histórico de diputados, www.congreso.es

96. La Razón. Periódico defensor de los intereses de Cuenca y de su provincia, 01/03/1923, 1.

97. $A B C, 11 / 02 / 1931,21$. 
«Boda aristocrática en Madrid» anunciaba, en 1924, un periódico nacional e ilustrado con fotografías, dando cuenta de la unión de «dos familias ilustres, los Enríquez de Luna, caballeros cruzados de la Orden militar de Montesa, y los Melgarejo, que ostentan la roja cruz de la Orden militar de Calatrava», celebrada en la iglesia del Corazón de María de Madrid, donde Severiano de Silva y Soria, hermano político del esposo José María Melgarejo, actuaba como testigo entre aristócratas y oficiales del Reino de España. ${ }^{98}$

Por consiguiente, todo lo anterior invita a matizar y completar unas líneas interpretativas de Edward Malefakis. Éste tomaba el ejemplo de los Silva y Soria como miembros de la «burguesía terrateniente», distinguiéndola de «los terratenientes más destacados [...] casi todos nobles cuyo origen se remontaba a la Edad Media o a comienzos de la Edad Moderna». ${ }^{99}$ Sin embargo, el estudio a ras del suelo y el micro-análisis del caso de Severiano de Silva y Soria bien demuestra que la larga duración de los órdenes aristocráticos y/o militares y religiosos, así como sus formas de Capital. Relacionadas con la tierra y la corona, dichas instituciones se regeneraron y complejizaron al mezclarse con familias asociadas a unas formas más recientes, más diversificadas de propiedades y de poderes políticos y/o económicos.

A finales de julio de 1931, durante el primer verano republicano, Severiano de Silva y Soria formaba parte del puñado de «Propietarios de fincas rústicas de importantes regiones afectadas por la reforma agraria, entre ellas Toledo» que firmaron un manifiesto constitutivo de la Asociación Nacional de Propietarios o Agrupación Nacional de Propietarios de Fincas Rústicas. ${ }^{100}$ Afirmando «defender los legítimos derechos de los mismos» ante los «inminentes peligros» y la «gravedad de las circunstancias » (respecto a la reforma agraria republicana), estos grandes propietarios llamaban a «todos los españoles propietarios» e insistían en «buscar la unión y la fuerza», afirmando que «velar por el legítimo patrimonio de nuestros hijos es uno de los primeros deberes». Más allá de la propiedad de la tierra y de la gran propiedad agraria la dimensión dinástica remitía a la cuestión distintiva.

Además, en los primeros meses de la Segunda República, el protagonismo asociativo de Severiano de Silva y Soria se duplicaba con un nuevo compromiso político. A principios de agosto de 1931, participó en Corral de Almaguer en un ritual de adhesión del partido Acción Popular, que había sido creado en las semanas que siguieron a la proclamación del régimen republicano y era el núcleo principal de la futura Confederación Española de las Derechas Autónomas (CEDA). ${ }^{101}$ Los dos diputados de Acción Popular por Toledo formaban parte de la minoría agraria, y ambos estaban presentes en el ritual político organizado en Corral de Almaguer, que fue abierto por una misa. ${ }^{102}$ Don Dimas de Madariaga y Almendros era originario de la localidad e hijo de Lorenzo de Madariaga Uriarte, ex-secretario del Juzgado

98. Blanco y Negro, 08/06/1924, 51.

99. Malefakis, Reforma... op. cit., 96, 92, 93.

100. El Castellano, 25/07/1931, 1. Proceden de esta fuente las citas que siguen, hasta la próxima nota.

101. Ver El Castellano, 03/08/1931,1.

102. Ver El Castellano, 03/08/1931, 1. 
de Corral de Almaguer y originario de la septentrional provincia de Álava. ${ }^{103}$ Don Ramón Molina Nieto, doctor en filosofía, teología y derecho canónigo, era además sacerdote de la Catedral Primada de España en Toledo. ${ }^{104}$ También estaba presente el líder de Acción Popular (y luego de la CEDA) José María Gil Robles, quien retrospectivamente confesaba: «Salvo contadas excepciones, los miembros de Acción Popular no habrían resistido la prueba de una declaración neta y clara de republicanismo». ${ }^{105}$ Por consiguiente, la dimensión monárquica y parlamentaria remitía al predominio de la concentración de la gran propiedad agraria en esta realidad social del Sur de Europa.

En Julio de 1932 y mientras los diputados de la minoría agraria trabajaban en la obstrucción parlamentaria de la ley de reforma agraria, el editorial del Boletín de la Agrupación de Propietarios de Fincas Rústicas era firmado por su vocal, Nicolás Alcalá Espinosa. ${ }^{106}$ Doctor en derecho y notario, elegido en 1931 diputado radical de Jaén, su familia era originaria de Baena, en la provincia de Córdoba, donde figuraba entre «los principales propietarios de la localidad». ${ }^{107}$ En el seno de la misma asociación que Severiano de Silva, tras la Agrupación de Propietarios de Fincas Rústicas, defendía unos intereses comunes a éste, eminentemente políticos, más allá de las distintas etiquetas políticas oficiales. Gran propietario cuyo poder era a la vez económico y político, como Severiano de Silva, Nicolás Alcalá Espinosa evocaba la noción de «atraso de la agricultura» española para descartarla como «un canto rodado de café madrileño» $y$, con connotaciones más violentas, asimilándola a unos «tópicos mortales». ${ }^{108}$ Sobre todo, apostaba explícitamente y peligrosamente sobre el hecho de que mientras se debatía democráticamente el tiempo jugaba a favor de sus intereses, a la vez económicos y políticos e inextricablemente unidos a la gran propiedad agraria:

La discusión de la reforma se desliza lenta, sin interés y sin dramatismos. Una vez aprobadas las bases ( ), habrá que reformar el Código Civil ( ). Habrá que dictar cinco o seis reglamentos más, ordenar la constitución de las Juntas y del Instituto de Reforma Agraria, hacer el inventario de las propiedades inmuebles... Por mucho que sea nuestro optimismo respecto a la vida ministerial, el arte es largo y la vida del Gobierno breve.

Sin embargo, con este juego de las demoras aumentaban cada vez más las radicalizaciones y polarizaciones vinculadas con el fenómeno masivo de la violencia política rural, desde los primeros meses de la Segunda República en adelante.

103. Acta de defunción de Lorenzo de Madariaga Uriarte (22/10/1916), Archivo Municipal del Ayuntamiento de Corral de Almaguer.

104. J. R. Díaz Sánchez Cid, El seminario conciliar de San Idelfonso de Toledo. Cien años de historia (18891989), Toledo, 1991, 109, 468.

105. J. M. Gil Robles, No fue posible la paz, Barcelona, 1968, 79.

106. Boletín de la Agrupación Nacional de Propietarios de Fincas Rústicas de España, n. 7, 07/1932, 1-3.

107. L. Álvarez Rey, Los deputados por Andalucia de la Segunda Republica 1931-1939, Sevilla, 2009, 246.

108. Boletin de la Agrupación Nacional de Propietarios de Fincas Rústicas de España, n. 7, 07/1932, 2. Proceden de esta fuente la citas que siguen, hasta la próxima nota.

Revista de historiografía 29, 2018, pp. 93-118 
El 21 de marzo de 1932, el diputado socialista por Toledo Fermín Blázquez tomaba la palabra en las Cortes:

Hace bastantes meses, en Corral de Almaguer, intentaron los obreros asociarse, y aquellos trabajadores, seguramente mal aconsejados, no voy a meterme en ello, esto es cierto que se reunieron en la plaza a fin de protestar contra el juez municipal por entender que este se había tomado atribuciones que no le correspondían. La Guardia civil, en vez de conducirse en términos de persuasión, y seguramente por miedo a ser agredida, disparó, cayendo cinco obreros muertos en la plaza y diez heridos. ${ }^{109}$

Se dirigía el diputado al señor Ministro de la guerra pidiéndole "para que el proceso pueda tramitarse con las garantías que corresponden, que aquellos guardias civiles que dispararon contra el pueblo sean trasladados», para que «en el proceso puedan declarar los obreros y los elementos que no son obreros, para decir la verdad de todo lo que allí ocurrió», ya que «esta misma Guardia civil, que sigue actuando en el pueblo, ejerce cierta presión para que los obreros no vayan a declarar la verdad». En este breve artículo es imposible detenerse en detalle sobre los sucesos de violencia política rural acaecidos en Corral de Almaguer el 22 de septiembre 1931, como en tantos pueblos del sur de España al principio de la Segunda República, tal y como lo indicó Edward Malefakis. ${ }^{10}$

«Todo cuanto es interesante ocurre en las sombras» insistía la microstoria y su esfuerzo explicativo inicial para articular las escalas, mientras de manera concomitante se creaba el concepto de «excepcional normal». ${ }^{111}$ «El Malefakis» había sido publicado unos años antes. Por consiguiente, a través del caso de Corral de Almaguer y de su violencia política rural que requeriría más espacio, se pueden observar unas dimensiones primordiales que remiten a las relaciones de fuerzas situadas en el espacio de la cuestión meridional europea. Por lo tanto, estos juegos de escalas se inscriben plenamente en la escritura de una historia a ras del suelo, minoritaria y cuya narración pone de relieve un «proceso de comprensión» inseparable del esfuerzo epistemológico para "conocer el por qué y el qué». ${ }^{112}$ Así es como, el caso excepcional normal de los violentos sucesos de Corral de Almaguer permite articular concretamente lo general con lo particular, a través del uso pionero del concepto de excepcional normal.

En un primer lugar, cabe indicar quiénes fueron las cinco víctimas de los sucesos de Corral de Almaguer: Juan Bravo Aguado (27 años, soltero), Santiago Díaz Fernández (35 años, casado), Daniel García Talavera (50 años, casado), Juan José Aparicio Zamora (45 años,

109. Diario de Sesiones de las Cortes Constituyentes de la República española, n. 139, 21/03/1932, 4635. Proceden de esta fuente las citas que siguen, hasta la próxima nota.

110. Malefakis, Reforma... op. cit., 351.

111. C. Ginzburg, Il formaggio e i vermi: il cosmo di un mugnaio del '500, Torino, 1976, 1; Grendi, "Microanalisi..." op. cit., 512.

112. D. Thompson (eds.), The Essential E. P. Thompson, Nueva York, 2001, 281, E. Hobsbawm, 'History from below. Some Reflections' in F. Kranz (Eds.), History from Below. Studies in Popular Protest and Ideology, Oxford, 1988, 13-27, 27, 26. 
casado) y Miguel Martínez Carrasco (18 años, soltero) eran «todos jornaleros». ${ }^{113}$ En un segundo lugar, cabe notar que Edward Malefakis señaló que «la mayoría de los decretos (del trabajo) fueron ratificados como leyes el 9 de septiembre de 1931». ${ }^{114}$ Por consiguiente, estos derechos colectivos inéditos, que Edward Malefakis calificaba de «revolución sin precedentes para la vida rural española», precisando que no fueron aplicados, sólo tenían una decena de días cuando acaecieron los violentos sucesos de Corral de Almaguer, el martes 22 septiembre 1931. ${ }^{115}$

En realidad habían empezado ya el domingo 20 septiembre de 1931, tras un decisivo altercado entre el juzgado municipal y los jornaleros masivamente movilizados, del que no resultaron muertos directamente. ${ }^{116} \mathrm{El} \mathrm{juez} \mathrm{municipal} \mathrm{de} \mathrm{Corral} \mathrm{de} \mathrm{Almaguer} \mathrm{era} \mathrm{el} \mathrm{señor}$ Barreda, su fiscal era Fernando Díaz Pimienta y su secretario era Pascual Gálvez. ${ }^{117}$ Resulta por consiguiente que éste combinó la función de secretario del juzgado municipal con la de corresponsal de El Castellano. En cuanto al juez municipal, bajo las órdenes de quien trabajaba Pascual Gálvez, su nombre completo era Manuel de la Barreda y Treviño. Ostentaba además los títulos distintivos de Caballero de la Orden de San Juan de Malta y de Comendador de San Raimundo de Peñafort, así como el de Conde de la Cañada y, por lo tanto, Grande de España al estar casado con Doña María de la Concepción Acedo-Rico y Sánchez de Ocaña, Jarava y Acedo-Rico. Formado como jurista bajo el Estado liberal del Reino de España, ejerció luego, durante más de treinta años, la profesión de Magistrado del régimen franquista y Presidente de la Audiencia de Cuenca. ${ }^{118}$

Juez y vinculado a la gran propiedad aristocrática, Manuel Barreda también estaba comprometido políticamente. A principio de agosto de 1931, fue él quien pagó el banquete político de Acción Popular invitando a Corral de Almaguer, además de los ya señalados diputados Gil Robles, Dimas de Madariaga y Ramón Molina Nieto, a decenas y decenas de incondicionales de toda la provincia de Toledo y de España. El menú proponía «entremeses María Luisa, huevos a la zíngara, langostinos mayonesa, ternera finacier» - siempre en palabras del corresponsal de El Castellano (de dudosos galicismos) - de «jamón de York con huevos hilados, ensalada raché, biscuit glacés, frutas variadas, vinos, café y licores». ${ }^{119}$

El juez municipal y propietario Manuel Barreda tomó la palabra invitando a brindar a «Madariaga, la representación genuina del regionalismo» a «Molina, el espíritu religioso» y a «Robles, la defensa de aquellos intereses que constituyen la médula de la Patria: los intereses agrarios». Con tales intereses en juego, era más difícil hacer respetar una justicia imparcial.

«Una de las causas que más influyen en todas esta anomalías es la especial situación en que se encuentra la vida municipal en varias localidades» notaba el Gobernador provincial

113. El Castellano, 23/09/1931, 1.

114. Malefakis, Reforma... op. cit., 204.

115. Malefakis, Reforma... op. cit., 204, 203.

116. El Castellano, 21/09/1931, 1.

117. El Castellano, 21/09/1931, 1.

118. J. de la Barreda y Acedo-Rico, Viejas familias de Alcalá de Henares, Madrid, 2003, 156, 157.

119. El Castellano, 03/08/1931, 1. Proceden de esta fuente las citas que siguen, hasta la próxima nota. 
de Toledo en septiembre 1931, pocas horas después de la altercación ocurrida en Corral de Almaguer y mientras se multiplicaban los sucesos de violencia política rural en los pueblos de la provincia. «Parece que no ha sido puesta en vigor la legislación social dictada por la República» notaba. ${ }^{120}$

«No dudo de la veracidad de los informes», certificaba a propósito del boicot de las leyes republicanas por los propietarios a través del no «cumplimiento de las bases de trabajo [y de la] abstención del laboreo de sus fincas». Sin embargo, esta urgencia no era la prioridad. «La autoridad [ ] no ha de vacilar en emplear los medios necesarios' afirmaba, en cambio (y mientras desaparecía la consciencia de la causalidad social), para que «vuelva a ser la provincia de Toledo lo que por su historia y su riqueza le corresponde en la economía nacional». Por consiguiente, existía una política de doble rasero, tanto para el orden público como para la economía agraria imbricada a éste. «Las declaraciones del nuevo gobernador [ ] causarán excelente efecto en la opinión toledana, especialmente entre las gentes de orden de la provincia» se alegraba El Castellano, de acuerdo con su línea editorial y con el público a quien se dirigía.

Durante todo el mes de agosto, los grandes propietarios de Toledo habían dirigido sus quejas al Ministro de la Gobernación, Miguel Maura, quien los recibió en su despacho, y nombró un nuevo Gobernador de la provincia el 16 de septiembre de $1931 .^{121}$ Retrospectivamente, Miguel Maura confesaba haber actuado sin haber entendido el fenómeno masivo y decisivo de la violencia política, ni la particularidad de sus lógicas sociales. «Cabo de vara o loquero mayor de un manicomio suelto y desbordado», así definía su función de Ministro de la Gobernación (de mayo a octubre de 1931), admitiendo haber ejercitado sus responsabilidades teniendo «atrofiada la mente cada una de las horas del día y de la noche con el obsesionante problema del orden público». ${ }^{122}$ La violencia política rural actuaba disimulando su lógica social.

Pocas horas después de la altercación implicando el juez Barreda, de la que había sido informado, mientras se negaba en escuchar la versión de los jornaleros de Corral de Almaguer, el Gobernador Luis Fernández de Valderrama y San José también declaraba solemnemente, parcialmente y oficialmente: «El Ministro de la Gobernación, señor Maura, que vigila con especial atención esta provincia, me ha dado instrucciones concretas», y afirmaba: «No se puede consentir impunemente que un país civilizado se convierta en una Cábila [sic]». ${ }^{123}$ Una vez más, tras la violencia política rural vinculada con la violencia verbal de los estereotipos aparecía la cuestión meridional europea y su dimensión mediterránea. Estas declaraciones oficiales del Gobernador de Toledo fueron pronunciadas la víspera de los sucesos de Corral de Almague, de la matanza de cinco jornaleros.

Algunos días después, el juez municipal y gran propietario Barreda dirigía una carta a El Castellano en la que informaba de que el teniente de la Benemérita don José Pascual Barba,

120. El Castellano, 21/09/1931, 1.

121. El Castellano, 12/08/1931, 1, Heraldo Toledano, 16/08/1931, 1, 27/08/1931, 1.

122. M. Maura, Así cayó Alfonso XIII: De una dictadura a otra, Madrid, 2007 (1ª ed. 1962), 376, 377.

123. El Castellano, 21/09/1931, 1. 
que «mandaba la fuerza» fue el oficial que «dio la orden de fuego». ${ }^{124} \mathrm{Da}$ la casualidad de que unos meses después este oficial estaba también en la cacería en honor del General Sanjurjo. Se trataba aún del primer invitado al que hacía referencia el artículo escrito en El Castellano por Pascual Gálvez - el secretario del juez Manuel Barreda -, indicando que José Pascual Barba formaba parte de las personalidades de Ocaña invitadas por Severiano de Silva y Soria a sus tierras de Corral de Almaguer. ${ }^{125}$ La fuerza se convierte en violencia al aparecer las contradicciones simbólicas e institucionales constitutivas de la autoridad económica incapacitando el poder político arbitrariamente encadenado a ésta.

Originario de la provincia vecina de Ciudad Real, también marcada por la gran propiedad agraria, José Pascual Barba, formado en la Academia de Infantería de Toledo fue, en los años 1920, militar colonial en la Compañía de Ametralladoras posicionada en Larache, Marruecos. ${ }^{126}$ El domingo 27 de septiembre de 1931, el General Sanjurjo y sus ayudantes se presentaron en Corral de Almaguer. El héroe de las guerras coloniales del Reino de España «felicitó al teniente don José Pascual Barba y guardias a sus órdenes por la prudencia, tacto y valor demostrados en los últimos días». ${ }^{127}$ Luego, el General Sanjurjo almorzó en una mesa reuniendo a «distinguidas personalidades» locales - siempre en palabras de El Castellano entre las cuales el teniente José Pascual Barba, el juez municipal Manuel Barreda y los jueces civiles (Soler) y militares (Manuel Pardo). Estas personas se encargaron de establecer la verdad oficial e institucional sobre la violencia política rural de los sucesos de Corral de Almaguer, mientras los jornaleros del pueblo, en cambio, estaban excluidos de esta deliberación directamente vinculada con dicha violencia, encadenada a ésta. La mayoría de las fuentes y su contenido reflejan esta disimetría.

Los sucesos de Corral de Almaguer implican unas relaciones de fuerzas situadas en el espacio transferible de la cuestión meridional europea. Las cifras oficiales de la gran propiedad en Toledo, Ocaña, Corral de Almaguer, etc., no cambian nada fundamental para el análisis de este fenómeno masivo de la violencia política rural, cuyo caso particular y paradigmático de Corral de Almaguer es un excepcional normal. ${ }^{128}$ Edward Malefakis bien había insistido en que la verdadera conversación científica ha de basarse en los números, para situarse también más allá de éstos. Por lo demás, en las conclusiones del libro dedicado a la guerra civil española que coordinó, el autor notaba que «las cosas empezaron a cambiar a partir de 1931 (...) [con] un Gobierno que rechazaba los procedimientos autoritarios a escala local». ${ }^{129}$ No iba sin dificultad, ni sin violencia.

124. El Castellano, $02 / 10 / 1931,4$.

125. El Castellano, 05/02/1932, 1.

126. Hoja de Servicios de José Pascual Barba, Archivo Central de la Dirección General de la Guardia Civil (Madrid).

127. El Castellano, 28/09/1931, 1. Proceden de esta fuente las citas que siguen, hasta la próxima nota.

128. Libros Registros de la Propiedad Expropiable, Provincia de Toledo, Tomo n. 190, Archivo del Instituto de Reforma y Desarrollo Agrario del Ministerio de la Agricultura (Madrid).

129. E. Malefakis, "Balance final", in E. Malefakis, La guerra de España (1936-1939), Madrid, 1996, 635664,643 .

Revista de historiografía 29, 2018, pp. 93-118 


\section{Conclusiones}

La historia agraria ambiciosa que articula concretamente las escalas de lo local a lo global puede inspirarse en la obra de Edward Malefakis y pensar por caso. Tal ha sido la demostración de este artículo poniendo España en su contexto socio-histórico a la vez nacional, europeo y global. No recuperar la historia agraria, así como la visión de conjunto interdisciplinaria del eminente historiador e hispanista estadounidense no estaría quizás tan lejos, para la comarca historiográfica de la historia agraria, del «egoísmo suicida» confesado retrospectivamente por el líder de la CEDA, que Edward Malefakis citaba en las conclusiones de su gran libro sobre la Segunda República española. ${ }^{130}$ En 2011, recordaba que este régimen democrático «fue vilmente asesinada por unas fuerzas atávicas y violentas». ${ }^{131}$ La violencia política rural generalizada formaba parte de éstas y de sus singularidades en el espacio transferible y global de la cuestión meridional europea. El uso pionero del concepto de excepcional normal lo da a entender de manera empírica. Y para remarcar los puntos fundamentales de nuestro argumento, ¿por qué no invitar a continuar labrando el campo de la historia agraria, tan importante para la Europa del Sud, abonándolo desde una perspectiva global? Sin duda, ello ayudaría a que las semillas que Edward Malefakis plantó hace décadas continúen germinando.

130. E. Malefakis, "Reforma...” op. cit., 447.

131. E. Malefakis, "La Segunda República y el revisionismo", El País, 12/06/2011, p. 35. 